Arq. Bras. Med. Vet. Zootec., v.66, n.3, p.903-910, 2014

\title{
Proteína bruta e energia metabolizável para codornas de corte de um a 14 dias de idade
}

[Crude protein and metabolizable energy for meat quail from 1 to 14 days of age]

\author{
R.S. Reis, S.L.T. Barreto, R.A. Torres, J.C.L. Muniz, M.O. Mendonça, G.S. Viana, \\ C.L.N. Ribeiro, S.L. Costa, M. Santos
}

Universidade Federal de Viçosa - Viçosa, MG

\begin{abstract}
RESUMO
Com o objetivo de avaliar diferentes níveis de proteína bruta e de energia metabolizável para codornas de corte de um a 14 dias de idade, foi realizado um estudo utilizando 840 codornas de corte, mistas. As aves foram distribuídas em arranjo fatorial $(2 \times 5)$ constituído por 10 tratamentos (dois níveis de energia metabolizável - 2800 e 3000kcal/kg e cinco níveis de proteína bruta - 22,0; 24,0; 26,0; 28,0 e 30,0\%), sete repetições com 12 aves cada. Foram avaliados os seguintes parâmetros: consumo de ração, ganho em peso aos sete e 14 dias de idade, conversão alimentar aos 14 dias e viabilidade. Verificou-se que codornas alimentadas com dietas com o nível energético mais baixo, $2800 \mathrm{kcal} / \mathrm{kg}$, apresentaram maior consumo. As aves que consumiram ração com menor nível de energia apresentaram maior peso aos sete dias de idade independentemente do nível de proteína bruta utilizado. O peso aos 14 dias de idade apresentou resposta quadrática com o acréscimo de proteína bruta na ração, sendo que dietas contendo $28,86 \%$ de PB proporcionaram melhor ganho independentemente do nível de energia utilizado. A conversão alimentar apresentou melhores resultados com o aumento do nível de proteína bruta da ração, independentemente do nível de energia metabolizável utilizado. Não foram observados efeitos significativos dos níveis de proteína e energia ou de sua interação sobre a viabilidade das aves. Rações contendo 30,0\% de proteína bruta e 2800 ou $3000 \mathrm{kcal} / \mathrm{kg}$ de energia metabolizável proporcionam satisfatórios resultados de desempenho para codornas de corte de um a 14 dias de idade.
\end{abstract}

Palavras-chave: Coturnix coturnix coturnix, crescimento, desempenho

\begin{abstract}
Aiming to evaluate the effect of different levels of crude protein and metabolizable energy for quails from 1 to 14 days of age, a study was conducted using 840 quails, mixed. The birds were distributed in a factorial arrangement (2x5) consisting of 10 treatments (two levels of metabolizable energy - 2,800 and 3,000kcal/kg and 5 levels of crude protein - 22.0, 24.0, 26.0, 28.0 and 30.0\%), 7 repetitions with 12 birds each. We evaluated the following parameters: feed intake, weight gain at 7 and 14 days of age, feed conversion at 14 days and viability. It was found that quail fed diets with the lowest energy level, $2,800 \mathrm{kcal} / \mathrm{kg}$, showed higher consumption. Birds fed diets with lower energy level had greater weight at 7 days of age regardless of the level of crude protein used. The weight at 14 days of age showed a quadratic response with the addition of crude protein in feed, showing that diets containing $28.86 \% \mathrm{CP}$ provide better gain regardless of the level of energy used. The feed showed better results with the increased level of dietary CP, regardless of level of metabolizable energy used. There were no significant effects of protein and energy levels or their interaction on viability. Diets with $30.0 \%$ crude protein and 2,800 or 3,000 kcal/kg metabolizable energy provide satisfactory performance results for quails from 1 to 14 days of age.
\end{abstract}

Keywords: Coturnix coturnix coturnix, growth, performance

Recebido em 5 de outubro de 2012

Aceito em 12 de dezembro de 2013

E-mail: renatareis51@yahoo.com.br 


\section{INTRODUÇÃO}

Em virtude do aumento do consumo mundial de carne, pesquisadores estão buscando alternativas que possam satisfazer as novas exigências dos consumidores na busca por produtos de origem animal de melhor qualidade. Nesse contexto, a produção de codornas para carne tem se tornado uma opção para os avicultores (Móri et al., 2005). Segundo Murakami (2007), a carne de codorna apresenta-se como um produto de alta qualidade, pois possui na sua composição ótimo perfil aminoacídico e teor de ácidos graxos, principalmente ômega 6 , e é rica em minerais, além de possuir características sensórias como odor, sabor e maciez de alta aceitação pela população.

No Brasil a coturnicultura tem sido dedicada à produção de ovos, sendo a carne um subproduto, visto que as carcaças comercializadas são oriundas de matrizes descartadas e apresentam baixa aceitação por parte do consumidor. Entretanto, com a recente expansão do setor, pode ser observado o aumento do interesse de produtores pela coturnicultura de corte. Contudo, a falta de material genético adequado disponível no mercado, a precariedade de dados sobre o desempenho e sobre as exigências nutricionais fazem com que criadores explorem a produção de carne de forma pouco organizada e empírica (Móri et al., 2005).

Existem poucas informações disponíveis sobre a nutrição de codornas de corte nas fases iniciais e de crescimento. Sabe-se que as condições nutricionais estabelecidas nas primeiras semanas de vida podem influenciar o desempenho e o rendimento no abate dessas aves, havendo, então, a necessidade da realização de trabalhos direcionados para a determinação das exigências nutricionais nestas fases. Ao serem analisadas algumas tabelas disponíveis, observa-se que não há uniformidade nos períodos referidos para as diferentes fases nem para os níveis nutricionais recomendados (Resende et al., 2004).

De acordo com Garcia (2002), é necessário o estabelecimento das exigências nutricionais para a espécie europeia, utilizada para corte, e o desenvolvimento de programas de alimentação visando à otimização do desempenho. Em adição, Silva et al. (2006) observam que planos de nutrição para a criação de codornas de corte, em condições brasileiras, ainda não foram desenvolvidos, mas podem ter contribuição importante na redução do custo de produção.

As fontes proteicas e energéticas das rações têm sido os componentes de maior participação nos custos das dietas, pois esses nutrientes influenciam diretamente o desempenho das codornas (Suida, 2001). São também considerados os componentes de maior importância na prática comercial, devendo, portanto, estar em quantidades suficientes para suprir as necessidades das aves, sem com isso onerar os seus custos de produção.

$\mathrm{Na}$ fase inicial de crescimento, de um a 14 dias de idade, as codornas japonesas podem aumentar em até 14 vezes o peso inicial, em razão da hipertrofia, principalmente dos músculos peitorais, do crescimento dos ossos e das vísceras (Silva e Costa, 2009). Desenvolvimento semelhante ocorre com as codornas de corte, demonstrado por Ton (2007), que avaliou a evolução da biomassa corporal acumulada nestas aves, ao longo do período experimental (um a 35 dias), e observou que, até aos 14 dias de idade, ocorre o maior acúmulo de tecido muscular.

Diante do exposto, objetivou-se avaliar diferentes níveis de proteína bruta e de energia metabolizável para codornas de corte de um a 14 dias de idade.

\section{MATERIAL E MÉTODOS}

O experimento foi conduzido no setor de Avicultura do Departamento de Zootecnia da Universidade Federal de Viçosa. Foram utilizadas 840 codornas de corte, mistas, durante o período de um a 14 dias de idade. As aves foram distribuídas em arranjo fatorial $(2 \times 5)$, constituído por 10 tratamentos (dois níveis de energia metabolizável - 2800 e $3000 \mathrm{kcal} / \mathrm{kg}$ e cinco níveis de proteína bruta - 22,0; 24,0; 26,0; 28,0 e $30,0 \%$ ), sete repetições com 12 aves cada.

As aves foram alojadas em gaiolas de recria, dispostas sobre bancadas de alvenaria com aproximadamente $120 \mathrm{~cm}$ de altura. Foram utilizadas três bancadas, sendo cada uma composta por 26 gaiolas com dimensões de $50 \mathrm{~cm}$ de largura e $50 \mathrm{~cm}$ de comprimento. $\mathrm{O}$ piso das gaiolas foi forrado com maravalha. 
Os bebedouros utilizados foram aqueles conhecidos como copos de pressão, na proporção de um bebedouro por gaiola; na segunda semana foram utilizados os bebedouros tipo nipple com copinho, sendo um para cada gaiola. Logo após o alojamento, as codorninhas foram orientadas quanto à presença de água, molhando-se o bico de algumas aves na lâmina d'água.

Os comedouros utilizados foram do tipo bandeja, na proporção de um por gaiola na primeira semana de idade das aves, quando estes foram substituídos por comedouros do tipo calha, posicionada na parte frontal das gaiolas.
O programa de iluminação foi de 24 horas de luz (artificial).

A temperatura ambiente da sala experimental foi verificada mediante um termômetro de máxima e mínima, e a umidade relativa do ar foi verificada por meio do termômetro de bulbo seco e bulbo úmido, ambos instalados junto às gaiolas.

As rações fornecidas para as aves (Tab. 1 e 2) foram balanceadas com base no conteúdo aminoacídico digestível dos alimentos, segundo Rostagno et al. (2005), e exigências nutricionais das codornas de corte conforme recomendado por Silva (2009) para a fase de um a 21 dias.

Tabela 1. Composições percentuais e calculadas das dietas experimentais na matéria natural

\begin{tabular}{|c|c|c|c|c|c|}
\hline \multicolumn{6}{|c|}{ Energia metabolizável $=2.800 \mathrm{kcal} / \mathrm{kg}$} \\
\hline \multirow{2}{*}{ Ingredientes } & \multicolumn{5}{|c|}{ Proteína bruta $(\%)$} \\
\hline & 22,0 & 24,0 & 26,0 & 28,0 & 30,0 \\
\hline Milho & 54,365 & 47,745 & 41,370 & 35,240 & 28,437 \\
\hline Farelo de soja (45\%) & 38,635 & 44,255 & 49,830 & 55,360 & 61,013 \\
\hline Óleo vegetal & 0,918 & 1,992 & 2,983 & 3,892 & 5,027 \\
\hline Calcário & 1,155 & 1,141 & 1,128 & 1,116 & 1,102 \\
\hline Fosfato bicálcico & 1,011 & 0,985 & 0,958 & 0,931 & 0,905 \\
\hline Sal & 0,381 & 0,382 & 0,382 & 0,383 & 0,383 \\
\hline L-lisina $\mathrm{HCl}(79 \%)$ & 0,000 & 0,000 & 0,000 & 0,000 & 0,000 \\
\hline DL-metionina (99\%) & 0,198 & 0,253 & 0,307 & 0,360 & 0,416 \\
\hline Cloreto de colina $(60 \%)$ & 0,100 & 0,100 & 0,100 & 0,100 & 0,100 \\
\hline Mistura mineral $^{1}$ & 0,070 & 0,070 & 0,070 & 0,070 & 0,070 \\
\hline Mistura vitamínica² & 0,100 & 0,100 & 0,100 & 0,100 & 0,100 \\
\hline Antioxidante $^{3}$ & 0,010 & 0,010 & 0,010 & 0,010 & 0,010 \\
\hline Coccisdiostático $^{4}$ & 0,050 & 0,050 & 0,050 & 0,050 & 0,050 \\
\hline Promotor de crescimento ${ }^{5}$ & 0,010 & 0,010 & 0,010 & 0,010 & 0,010 \\
\hline Inerte $^{6}$ & 2,998 & 2,908 & 2,702 & 2,379 & 2,377 \\
\hline TOTAL & 100,00 & 100,00 & 100,00 & 100,00 & 100,00 \\
\hline \multicolumn{6}{|l|}{ Composição calculada } \\
\hline Proteína bruta $(\%)$ & 22,00 & 24,00 & 26,00 & 28,00 & 30,00 \\
\hline Energia metabolizável (kcal/kg) & 2.800 & 2.800 & 2.800 & 2.800 & 2.800 \\
\hline Lisina digestível (\%) & 1,099 & 1,225 & 1,358 & 1,486 & 1,616 \\
\hline Met + cis. digestível (\%) & 0,803 & 0,897 & 0,991 & 1,085 & 1,179 \\
\hline Treonina digestível (\%) & 0,753 & 0,824 & 0,894 & 0,964 & 1,035 \\
\hline Triptofano digestível (\%) & 0,249 & 0,276 & 0,304 & 0,331 & 0,359 \\
\hline Sódio $(\%)$ & 0,17 & 0,17 & 0,17 & 0,17 & 0,17 \\
\hline Cálcio $(\%)$ & 0,80 & 0,80 & 0,80 & 0,80 & 0,80 \\
\hline Fósforo disponível (\%) & 0,30 & 0,30 & 0,30 & 0,30 & 0,30 \\
\hline
\end{tabular}

${ }^{\mathrm{T}}$ Composição/kg de produto: manganês: $160 \mathrm{~g}$, ferro: $100 \mathrm{~g}$, zinco: $100 \mathrm{~g}$, cobre: $20 \mathrm{~g}$, cobalto: $2 \mathrm{~g}$, iodo: $2 \mathrm{~g}$, excipiente q.s.p.: 1000 g. ${ }^{2}$ Composição/kg de produto: vit. A:12.000.000UI, vit $\mathrm{D}_{3}: 3.600 .000 U$ U, vit. E: $3.500 \mathrm{UI}$, vit $\mathrm{B}_{1}$ : $2.500 \mathrm{mg}$, vit $\mathrm{B}_{2}: 8.000 \mathrm{mg}$, vit $\mathrm{B}_{6}: 5.000 \mathrm{mg}$, ácido pantotênico: $12.000 \mathrm{mg}$, biotina: $200 \mathrm{mg}$, vit. K: $3.000 \mathrm{mg}$, ácido fólico: $1.500 \mathrm{mg}$, ácido nicotínico: $40.000 \mathrm{mg}$, vit. $\mathrm{B}_{12}: 20.000 \mathrm{mg}$, selênio: $150 \mathrm{mg}$, veículo q.s.p.: $1.000 \mathrm{~g}$. ${ }^{3}$ BHT- butil-hidroxitolueno. ${ }^{4}$ Coxistac $12 \% .{ }^{5}$ Avilamicina $10 \%$. ${ }^{6}$ Areia lavada. 
Tabela 2. Composições percentuais e calculadas das dietas experimentais na matéria natural

\begin{tabular}{|c|c|c|c|c|c|}
\hline \multicolumn{6}{|c|}{ Energia metabolizável $=3.000 \mathrm{kcal} / \mathrm{kg}$} \\
\hline \multirow{2}{*}{ Ingredientes } & \multicolumn{5}{|c|}{ Proteína bruta (\%) } \\
\hline & 22,0 & 24,0 & 26,0 & 28,0 & 30,0 \\
\hline Milho & 54,365 & 47,745 & 41,370 & 35,240 & 28,437 \\
\hline Farelo de soja (45\%) & 38,635 & 44,255 & 49,830 & 55,360 & 61,013 \\
\hline Óleo vegetal & 3,193 & 4,267 & 5,258 & 6,167 & 7,303 \\
\hline Calcário & 1,155 & 1,141 & 1,128 & 1,116 & 1,102 \\
\hline Fosfato bicálcico & 1,011 & 0,985 & 0,958 & 0,931 & 0,905 \\
\hline Sal & 0,381 & 0,382 & 0,382 & 0,383 & 0,383 \\
\hline L-lisina $\mathrm{HCl}(79 \%)$ & 0,000 & 0,000 & 0,000 & 0,000 & 0,000 \\
\hline DL-metionina (99\%) & 0,198 & 0,253 & 0,307 & 0,360 & 0,416 \\
\hline Cloreto de colina (60\%) & 0,100 & 0,100 & 0,100 & 0,100 & 0,100 \\
\hline Mistura mineral $^{1}$ & 0,070 & 0,070 & 0,070 & 0,070 & 0,070 \\
\hline Mistura vitamínica² & 0,100 & 0,100 & 0,100 & 0,100 & 0,100 \\
\hline Antioxidante $^{3}$ & 0,010 & 0,010 & 0,010 & 0,010 & 0,010 \\
\hline Coccisdiostático $^{4}$ & 0,050 & 0,050 & 0,050 & 0,050 & 0,050 \\
\hline Promotor de crescimento ${ }^{5}$ & 0,010 & 0,010 & 0,010 & 0,010 & 0,010 \\
\hline Inerte $^{6}$ & 0,722 & 0,633 & 0,426 & 0,103 & 0,101 \\
\hline Total & 100,00 & 100,00 & 100,00 & 100,00 & 100,00 \\
\hline \multicolumn{6}{|l|}{ Composição calculada } \\
\hline Proteína bruta $(\%)$ & 22,00 & 24,00 & 26,00 & 28,00 & 30,00 \\
\hline Energia metabolizável (kcal/kg) & 3.000 & 3.000 & 3.000 & 3.000 & 3.000 \\
\hline Lisina digestível (\%) & 1,099 & 1,225 & 1,358 & 1,486 & 1,616 \\
\hline Met + cis. digestível (\%) & 0,803 & 0,897 & 0,991 & 1,085 & 1,179 \\
\hline Treonina digestível (\%) & 0,753 & 0,824 & 0,894 & 0,964 & 1,035 \\
\hline Triptofano digestível (\%) & 0,249 & 0,276 & 0,304 & 0,331 & 0,359 \\
\hline Sódio $(\%)$ & 0,17 & 0,17 & 0,17 & 0,17 & 0,17 \\
\hline Cálcio $(\%)$ & 0,80 & 0,80 & 0,80 & 0,80 & 0,80 \\
\hline Fósforo disponível (\%) & 0,30 & 0,30 & 0,30 & 0,30 & 0,30 \\
\hline
\end{tabular}

${ }^{1}$ Composição/kg de produto: manganês: $160 \mathrm{~g}$, ferro: $100 \mathrm{~g}$, zinco: $100 \mathrm{~g}$, cobre: $20 \mathrm{~g}$, cobalto: $2 \mathrm{~g}$, iodo: $2 \mathrm{~g}$, excipiente q.s.p.: 1000 g. ${ }^{2}$ Composição/kg de produto: vit. A:12.000.000UI, vit $\mathrm{D}_{3}: 3.600 .000 \mathrm{UI}$, vit. E: $3.500 \mathrm{UI}$, vit $\mathrm{B}_{1}$ :2.500mg, vit $\mathrm{B}_{2}: 8.000 \mathrm{mg}$, vit $\mathrm{B}_{6}: 5.000 \mathrm{mg}$, ácido pantotênico: $12.000 \mathrm{mg}$, biotina: $200 \mathrm{mg}$, vit. $\mathrm{K}: 3.000 \mathrm{mg}$, ácido fólico: $1.500 \mathrm{mg}$, ácido nicotínico: $40.000 \mathrm{mg}$, vit. $\mathrm{B}_{12}: 20.000 \mathrm{mg}$, selênio: $150 \mathrm{mg}$, veiculo q.s.p.: $1.000 \mathrm{~g}$. ${ }^{3} \mathrm{BHT}$ Butil-hidroxitolueno. ${ }^{4}$ Coxistac $12 \% .{ }^{5}$ Avilamicina $10 \%$. ${ }^{6}$ Areia lavada.

Foram avaliados os seguintes parâmetros: consumo de ração, ganho em peso de um a sete e de um a 14 dias de idade, conversão alimentar de um a 14 dias de idade e viabilidade das aves de um a 14 dias de idade.

A fim de se obter o consumo de ração, ao final dos 14 dias foi realizada a divisão da quantidade de ração consumida pelo número de aves de cada tratamento. No caso de aves mortas durante o período, o seu consumo médio foi descontado e corrigido, obtendo-se o consumo médio verdadeiro para a unidade experimental em questão.
Para avaliação do ganho em peso, todas as aves foram pesadas ao início, aos sete dias e ao término do experimento (14 dias).

A conversão alimentar foi calculada dividindo-se o consumo de ração pelo ganho de peso corporal acumulado no período.

A mortalidade das aves foi subtraída do número total de aves vivas, sendo os valores obtidos convertidos em porcentagem no final do período experimental.

Os parâmetros avaliados foram submetidos à análise de variância a $5 \%$ de probabilidade utilizando-se o programa SAEG - Sistema para Análises Estatísticas e Genéticas (Sistema..., 2007). 


\section{RESULTADOS E DISCUSSÃO}

A média das temperaturas mínima e máxima, registradas durante o período experimental, está apresentada na Tab. 3.

Conforme os valores observados para as temperaturas na primeira e segunda semanas de idade das aves, é possível inferir que as codornas estiveram expostas a ligeiras condições de estresse por calor em ambas as semanas.

Na Tab. 5 encontram-se os dados referentes aos parâmetros de desempenho das codornas.

Tabela 3. Valores de temperatura e umidade relativa do ar (UR), registradas no galpão experimental durante os períodos de um a sete e de oito a 14 dias de idade das aves

\begin{tabular}{ccccc}
\hline \multirow{2}{*}{ Horário } & \multicolumn{2}{c}{ Temperatura do ar $\left({ }^{\circ} \mathrm{C}\right)$ no período de 1 a 7 dias de idade } & \multirow{2}{*}{ UR $(\%)$} \\
\cline { 2 - 3 } & Máxima & Mínima & Bulbo seco & \\
\hline 8h & $37,2 \pm 2,5$ & $29,8 \pm 3,4$ & $33,6 \pm 1,2$ & $66,8 \pm 8,5$ \\
$16 \mathrm{~h}$ & $39,1 \pm 3,6$ & $31,6 \pm 3,2$ & $31,0 \pm 3,3$ & $69,7 \pm 9,4$ \\
\hline & Temperatura do ar $\left({ }^{\circ} \mathrm{C}\right)$ no período de 8 a 14 dias de idade & \\
\cline { 2 - 4 } & Máxima & Mínima & Bulbo seco & \\
\cline { 2 - 3 } 8h & $28,7 \pm 1,3$ & $21,4 \pm 2,2$ & $27,4 \pm 2,0$ & $71,0 \pm 4,3$ \\
$16 \mathrm{~h}$ & $29,6 \pm 2,9$ & $24,5 \pm 2,8$ & $25,1 \pm 3,3$ & $65,2 \pm 8,8$ \\
\hline
\end{tabular}

Tabela 4. Desempenho das codornas de corte alimentadas com rações contendo diferentes níveis de proteína bruta e energia metabolizável

\begin{tabular}{|c|c|c|c|c|c|c|}
\hline \multirow{2}{*}{$\begin{array}{l}\text { Níveis de energia } \\
\text { metabolizável } \\
\text { kcal/kg }\end{array}$} & \multicolumn{5}{|c|}{ Níveis de proteína bruta (\%) } & \multirow{2}{*}{ Média } \\
\hline & 22 & 24 & 26 & 28 & 30 & \\
\hline \multicolumn{7}{|c|}{ Peso 7 dias (gramas) } \\
\hline 2800 & 29,738 & 32,147 & 31,119 & 32,151 & 33,339 & $31,699^{\mathrm{a}}$ \\
\hline 3000 & 27,420 & 28,513 & 28,500 & 28,520 & 28,254 & $28,241^{\mathrm{b}}$ \\
\hline Média & 28,579 & 30,330 & 29,810 & 30,335 & 30,797 & $\mathrm{CV}(\%)=6,768$ \\
\hline \multicolumn{7}{|c|}{ Peso 14 dias $^{1}$ (gramas) } \\
\hline 2800 & 76,757 & 84,672 & 86,405 & 87,555 & 92,130 & 85,504 \\
\hline 3000 & 76,136 & 83,574 & 83,995 & 88,432 & 86,217 & 83,670 \\
\hline Média & 76,447 & 84,123 & 85,200 & 87,994 & 89,174 & $\mathrm{CV}(\%)=8,513$ \\
\hline \multicolumn{7}{|c|}{ Consumo de ração de 1 a 14 dias (gramas) } \\
\hline 2800 & 130,214 & 130,334 & 139,152 & 135,009 & 138,665 & $134,675^{\mathrm{b}}$ \\
\hline 3000 & 122,374 & 132,100 & 125,261 & 126,091 & 120,447 & $125,255^{\mathrm{a}}$ \\
\hline Média & 126,294 & 131,217 & 132,207 & 130,550 & 129,556 & $\mathrm{CV}(\%)=8,470$ \\
\hline \multicolumn{7}{|c|}{ Ganho em peso de 1 a 14 dias $^{2}$ (gramas) } \\
\hline 2800 & 67,140 & 79,147 & 76,964 & 78,221 & 82,487 & 76,792 \\
\hline 3000 & 66,958 & 74,264 & 74,519 & 78,944 & 76,898 & 74,317 \\
\hline Média & 67,049 & 76,706 & 75,742 & 78,583 & 79,693 & $\mathrm{CV}(\%)=8,871$ \\
\hline \multicolumn{7}{|c|}{ Conversão alimentar de 1 a 14 dias $^{3}$} \\
\hline 2800 & 1,943 & 1,651 & 1,813 & 1,743 & 1,685 & 1,766 \\
\hline 3000 & 1,833 & 1,780 & 1,684 & 1,597 & 1,569 & 1,693 \\
\hline Média & 1,888 & 1,716 & 1,749 & 1,670 & 1,627 & $\mathrm{CV}(\%)=7,018$ \\
\hline \multicolumn{7}{|c|}{ Viabilidade de 1 a 14 dias ${ }^{\text {ns }}$} \\
\hline 2800 & 99,0 & 98,94 & 98,94 & 97,42 & 98,94 & 98,65 \\
\hline 3000 & 97,42 & 96,36 & 98,94 & 98,94 & 96,36 & 97,60 \\
\hline Média & 98,21 & 97,65 & 98,94 & 98,18 & 97,65 & $\mathrm{CV}(\%)=13,053$ \\
\hline
\end{tabular}

Médias seguidas por letras diferentes na coluna diferem entre si pelo teste $\mathrm{F}(\mathrm{p}>0,05)$.

$\mathrm{ns}=$ efeito não significativo. ${ }^{1}$ Efeito linear $(\mathrm{p}<0,01)$ : $\mathrm{y}=46,4748+1,46585 \mathrm{x}, \mathrm{R}^{2}=0,86 .{ }^{2}$ Efeito quadrático $(\mathrm{p}<0,05)$ : $y=-118,276+13,6978 x-0,237300 x^{2}, R^{2}=0,86 .^{3}$ Efeito linear $(p<0,01): y=52,38427+1,29346 x, R^{2}=0,74$. 
Não houve interação significativa entre os níveis de energia metabolizável e os níveis de proteína bruta da dieta para nenhum dos parâmetros avaliados.

O nível energético da dieta influenciou o consumo alimentar, de modo que codornas alimentadas com dietas com o nível energético mais baixo, $2800 \mathrm{kcal} / \mathrm{kg}$, apresentaram maior consumo $(\mathrm{P}<0,01)$. Resultados semelhantes foram obtidos por Murakami et al. (1993), os quais observaram maior consumo de dieta em codornas japonesas alimentadas com dietas contendo $2800 \mathrm{kcal}$ de EM/kg, em comparação às alimentadas com dietas contendo $3000 \mathrm{kcal}$ de $\mathrm{Em} / \mathrm{kg}$ de dieta do primeiro ao $42^{\circ}$ dia de idade. Esses dados também corroboram os encontrados por Freitas et al. (2006), que, ao avaliarem o efeito de diferentes níveis de proteína bruta (20, 22,24 e 26\%) e energia metabolizável (2.565, $2.715,2.865$ e $3.015 \mathrm{kcal} / \mathrm{kg}$ ), verificaram redução linear no consumo de ração com o aumento do nível de energia da dieta.

Segundo Leeson et al. (1996), os animais tendem a regular o consumo de ração de forma a ingerir quantidade constante de energia. Por isso, alteram o consumo de ração de acordo com o nível de energia. Os resultados obtidos neste estudo indicam que as codornas de corte se alimentaram para satisfazer, primeiramente, suas exigências de energia, comportamento semelhante ao dos frangos de corte (Albino e Silva, 1996; Sakomura, 1996). Esses resultados também corroboram a teoria quimiostática da ingestão de alimentos (Ávila et al., 2003).

Não houve efeito dos níveis de proteína sobre o consumo de ração. Esses dados corroboram os de Veloso et al. (2012), os quais avaliaram cinco níveis de proteína bruta $(18,20,22,24$ e $26 \%$ de PB) com três níveis de energia $(2.700,2.900$ e $3.100 \mathrm{kcal} \mathrm{EM} \mathrm{kg}$ ) na dieta de codornas de corte na fase inicial de crescimento e também não verificaram efeito significativo dos níveis de proteína sobre o consumo de ração. Segundo Freitas et al. (2006), não há efeito da PB sobre o consumo de ração em codornas de corte porque a ação da proteína sobre o $\mathrm{CR}$ não é resultado apenas da quantidade de PB fornecida na ração, mas também da qualidade (em relação aos aminoácidos) que esta ração contém.
O peso corporal das aves aos sete dias de idade foi influenciado pelo nível de energia metabolizável da ração $(\mathrm{P}<0,01)$, na medida em que foi observado que aves que consumiram ração com menor nível de energia, $2800 \mathrm{kcal} / \mathrm{kg}$, apresentaram maior peso nessa idade independentemente do nível de proteína bruta utilizado. Segundo Macari et al. (1994), na ave jovem, a absorção de gordura é limitada, e apenas quando a estrutura do enterócito alcança seu pleno desenvolvimento é que a absorção de lipídeos se efetiva, o que ocorre após duas ou três semanas de vida pós-natal, fase em que os mecanismos de digestão e absorção alcançam sua plenitude. Dunnington e Siegel (1995), ao estudarem a atividade de enzimas em frangos selecionados para alto/baixo peso vivo aos 42 dias de idade, observaram que a atividade relativa da enzima lipase atingiu níveis mais elevados aos oito dias de idade. Ao contrário do obtido no referido estudo, Nir et al. (1993) observaram que a atividade da lipase aumentou gradualmente até atingir cerca de 40 vezes seu valor aos 14 dias de idade. Entretanto, em estudo realizado por Nitsan et al. (1991), a atividade específica de lipase no pâncreas de frangos de corte ao nascimento até 20 dias diminuiu durante os três a seis primeiros dias após o nascimento e aumentou cerca de 10-20\% aos 21 dias.

Aos 14 dias de idade, pode ser verificado que a energia não mais influenciou o peso das aves, o que pode levar a inferir que a capacidade digestiva delas já tenha alcançado plenitude. No entanto, pode ser observado que o aumento do teor de proteína bruta, de 22 para $30 \%$, proporcionou aumento $(\mathrm{P}<0,01)$ do peso das aves nessa idade. A razão entre energia e proteína para máximo desempenho encontrada neste estudo foi de 93 e 100 para os níveis de 2800 e $3000 \mathrm{kcal} / \mathrm{kg}$, respectivamente.

Shrivastav e Panda (1990), com o objetivo de determinar as exigências de energia e proteína e a razão ótima entre elas para codornas de corte em crescimento, verificaram que essas aves apresentam máximo desempenho com dietas com relação de energia:proteína de 96 a 105 e conteúdo energético de $2803,82 \mathrm{kcal}$ de EM/kg, valores estes um pouco superiores aos encontrados no presente estudo.

Para o parâmetro ganho em peso, foi observada resposta quadrática $(\mathrm{P}<0,01)$ dos níveis de 
proteína bruta segundo a equação $\mathrm{y}=-118,276+$ $13,6978 x-0,237300 x^{2}, R^{2}=0,86$, indicando que dietas contendo $28,86 \%$ de PB proporcionam melhor ganho independentemente do nível de energia utilizado. Entretanto, Oliveira et al. (2002), ao testarem cinco níveis de proteína (18, $20,22,24$ e $26 \%)$ e três de energia $(2.800,3.000$ e $3.200 \mathrm{kcal}$ de EM/kg) para codornas, verificaram que, para o máximo ganho em peso no período total de cinco a 49 dias de idade, as rações deveriam conter $26 \%$ de PB e $3.200 \mathrm{kcal}$ de EM/kg. Contudo, Corrêa et al. (2008), ao estudarem efeito dos níveis de proteína bruta no peso corporal de codornas de corte, observaram que aves alimentadas com maiores níveis de PB $(30 \%)$ apresentaram maior peso corporal do nascimento até 21 dias de idade. De maneira contrária, Veloso et al. (2012) não observaram efeito dos níveis de proteína bruta sobre o ganho em peso de codornas de corte na fase inicial de crescimento.

Freitas et al. (2006), ao trabalharem com codornas de corte, não observaram efeito dos níveis de proteína bruta sobre o ganho em peso. Em contrapartida, esses autores observaram que o ganho em peso aumentou linearmente com o acréscimo do nível da energia da ração, na medida em que, para cada kcal de aumento na energia, houve acréscimo de $0,017 \mathrm{~g}$ no ganho em peso das aves durante o período estudado. Contudo, Corrêa et al. (2007), ao avaliarem quatro níveis de proteína bruta $(22,0 ; 24,0$; 26,0 ; e 28,0\%) em fatorial com dois níveis de energia metabolizável (2900 e 3100kcal $/ \mathrm{kg}$ ) para codornas de corte em crescimento, observaram aumento no ganho em peso das aves aos 21 dias até os níveis de 27,08 e 27,0\% de proteína bruta, respectivamente, e diminuição do ganho em peso a partir desses níveis.

A conversão alimentar foi influenciada $(\mathrm{P}<0,03)$ pelo nível de proteína da ração, pois observaram-se melhores resultados para esse parâmetro com o aumento do nível de proteína bruta, independentemente do nível de energia metabolizável utilizado. Esses resultados corroboram os de Corrêa et al. (2007), os quais verificaram que, com o aumento dos níveis de proteína bruta das dietas de codornas de corte do sétimo ao $21^{\circ}$ dia, houve uma melhora linear da conversão alimentar.
De forma contrária a esses estudos, Freitas et al. (2006) não verificaram efeito dos níveis de proteína bruta sobre a conversão alimentar de codornas japonesas em crescimento, entretanto esses autores observaram melhora na conversão com o aumento do nível de energia metabolizável, uma vez que, para cada kcal de aumento na energia da ração, os autores constataram uma redução média de 0,001 pontos na conversão alimentar.

Não foram observados efeitos significativos dos níveis de proteína e energia ou de sua interação sobre a viabilidade das aves. Efeito semelhante foi verificado por Freitas et al. (2006), os quais obtiveram uma viabilidade de $97,92 \%$. Estudos sobre a viabilidade de produção de codornas são escassos, uma vez que a maioria das mortes nos primeiros dias de vida das aves se dá em decorrência de acidentes e não por efeito das rações utilizadas.

\section{CONCLUSÃO}

Rações com 30,0\% de proteína bruta e 2800 ou $3000 \mathrm{kcal} / \mathrm{kg}$ de energia metabolizável proporcionam satisfatórios resultados de desempenho para codornas de corte de um a 14 dias de idade. Entretanto, mais estudos devem ser realizados a fim de se determinarem as exigências desses nutrientes para codornas de corte nesta fase, uma vez que, pelo observado, essas aves respondem positivamente ao aumento do teor de proteína bruta na ração.

\section{AGRADECIMENTOS}

Ao CNPq e à Granja Fujikura.

\section{REFERÊNCIAS}

ALBINO, L.F.T.; SILVA, M.A. Valores nutritivos de alimentos para aves e suínos determinados no Brasil. In: SIMPÓSIO INTERNACIONAL SOBRE EXIGÊNCIAS NUTRICIONAIS DE AVES E SUÍNOS, 1996, Viçosa. Anais... Viçosa: [s.n.] 1996. p.303-318.

ÁVILA, R.P.; SOARES, R.T.R.N.; CORDEIRO, M.D. et al. Níveis de energia para codornas japonesas na fase de crescimento. In: REUNIÃO ANUAL DA SOCIEDADE BRASILEIRA DE ZOOTECNIA, 40. 2003, Santa Maria. Anais... Santa Maria: [s.n.] 2003. (Resumo) 
CORRÊA, G.S.S.; SILVA, M.A.; CORRÊA, A.B. et al. Exigência de proteína bruta e 15 energia metabolizável para codornas de corte EV1 em crescimento. Arq. Bras. Med. Vet. Zootec., v.59, p.1278-1286, 2007.

CORRÊA, G.S.S.; SILVA, M.A.; CORRÊA A.B. et al. Nível de proteína bruta para codornas de corte durante o período de crescimento. Arq. Bras. Med. Vet. Zootec., v.60, p.209-217, 2008.

DUNNINGTON, E.A.; SIEGEL, P.B. Enzyme activity and organ development in newly hatched chicks selected for high or low eight-week body weight. Poult. Sci., v.74, p.761-70, 1995.

FREITAS, A.C.; FUENTES, M.F.F.; FREITAS, E.R. et al. Níveis de proteína bruta e energia metabolizável na ração para codornas de corte. Rev. Bras. Zootec., v.35, p.1705-1710, 2006.

GARCIA, E.A. Codornas para produção de carne. In: SIMPÓSIO INTERNACIONAL DE COTURNICULTURA - Novos conceitos aplicados à produção de codornas, 1., 2002, Lavras. Anais... Lavras: [s.n.] 2002. p.97-108.

LEESON, S.; YERSIN, A.; VOLKER, L. et al. Broiler response to energy or energy and protein dilution in the finisher diet. Poult. Sci., v.75, p.522-528, 1996.

MACARI, M.; FURLAN, R.; GONZALES, E Fisiologia aviária aplicada à frangos de corte. Jaboticabal: Editora FUNEP, 1994. 296p.

MÓRI, C.; GARCIA, E.A.; PAVAN, A.C. et al. Desempenho e rendimento de carcaça de quatro grupos genéticos de codornas para produção de carne. Rev. Bras. Zootec., v.34, p.870-876, 2005.

MURAKAMI, A.E.; GARCIA, E.R.M.; SOUZA, L.M.G. Composição e características organolépticas da carne de codorna. In: III SIMPÓSIO INTERNACIONAL E II CONGRESSO BRASILEIRO DE COTURNICULTURA, 2007, Lavras. Anais... Lavras: [s.n.] 2007. p.22-31.

MURAKAMI, A.E.; MORAES, V.M.B.; ARIKI, J. et al. Níveis de proteína e energia em rações para codornas japonesas (Coturnix coturnix japonica) em crescimento. Rev. Bras. Zootec., v.22, p.534-540, 1993.

NIR, I.; LEVANON, M. Effect of posthatch holding time on performance and on residual yolk and liver composition. Poult. Sci., v.72, p.1994-1997, 1993.
NITSAN, Z.; BEN-AVRAHAM, G.; ZOREF, Z.; NIR, I. Growth and development of the digestive organs and some enzymes in broiler chicks after hatching. Brit. Poult. Sci., v.32, p.515-523, 1991.

RESENDE, M.J.M.; FLAUZINA, L.P.; Mc MANUS, C. et al. Desempenho produtivo e biometria das vísceras de codornas francesas alimentadas com diferentes níveis de energia metaboliável e proteína bruta. Acta. Sci. Ani. Sci., v.26, p.353-358, 2004.

ROSTAGNO, H.S.; ALBINO, L.F.T.; DONZELE, J.L. et al. Tabelas Brasileiras para Aves e Suínos. Composição de Alimentos e Exigências Nutricionais. Viçosa: Editora UFV, 2005. 186p.

SAKOMURA, N.K. Exigências nutricionais das aves utilizando o modelo fatorial. In: SIMPÓSIO INTERNACIONAL SOBRE EXIGÊNCIAS NUTRICIONAIS DE AVES E SUÍNOS, 1996, Viçosa. Anais... [s.n.] 1996. p.319-344.

SHRIVASTAV, A.K.; PANDA, B. Effect of reducing dietary calorie to protein ratio at different energy concentration on the performance of broilers quail. Ind. J. Ani. Sci., v.25, p.79-87, 1990.

SILVA, J.H.V.; COSTA, F.G.P. Tabelas para Codornas Japonesas e Europeias. Jaboticabal: Editora Funep, 2009. 110p.

SILVA E.L.; SILVA, J.H.V.; JORDÃO FILHO, J. et al. Redução dos níveis de proteína e suplementação aminoacídica em rações para codornas europeias (Coturnix coturnix coturnix). Rev. Bras. Zootec., v.35, p.822-829, 2006.

SUIDA, D. Formulação por proteína ideal e consequências técnicas, econômicas e ambientais. In: SIMPÓSIO INTERNACIONAL DE NUTRIÇÃO ANIMAL: PROTEÍNA IDEAL, ENERGIA LÍQUIDA E MODELAGEM, 1., 2001, Santa Maria. Anais... [s.n.] 2001.

TON, A.P.S. Exigências de lisina digestível e energia metabolizável de codornas de corte (Coturnix coturnix sp) em crescimento, com base no conceito de proteína ideal. 2007. 41p. Dissertação (Mestrado em Zootecnia) - Universidade Estadual de Maringá.

SISTEMA para análises estatísticas - SAEG. Versão 9.1. Universidade Federal De Viçosa - UFV: Fundação Arthur Bernardes, 2007. 142p.

VELOSO, R.C.; PIRES, A.V.; TIMPANI, V.D.; DRUMOND, et al. Níveis de proteína bruta e energia metabolizável para codornas de corte. Acta. Sci. Ani. Sci., v.34, p.169-174, 2012. 